This is a post-peer-review, pre-copyedit version of an article published in Science Engineering and Ethics. The final authenticated version is available online at: $\mathrm{http}: / / \mathrm{doi.org} / 10.1007 / \mathrm{s} 11948$ 019-00083-6 


\title{
An empirical study on construction process corruption susceptibility: A vignette of international
}

\section{expertise}

\begin{abstract}
Construction process (CP) stages are argued to be vulnerable to the prevalence of corrupt practices. However, the validity of this argument has not been empirically explored in the extant literature of construction management. Therefore this study, examines CP stage susceptibility to corruption and its most prominent forms of corrupt activities (within the respective stages). A total of forty-four projectrelated professionals were involved in an expert survey to assess such susceptibilities and the criticality of the identified corrupt activities at each stage. A comparative study of expert views from developing regions against experts from developed regions is conducted. Expert scoring results revealed that three $\mathrm{CP}$ stages are most susceptible, namely: project execution, pre-qualification and tender stages. Such results were confirmed by application of the Mann-Whitney U test statistics tool, showing wide disparities in seven out of eleven identical stages. This study is intended to incite polemic discussions and greater empirical evidence based research from scholars in both developed and developing countries. This study adds to the extant literature corruption-related works in CP through deeper understanding of the dynamic nature of corrupt practices involved in CP stages in developing countries. Practically, it intends to offer a veritable plethora of information on the critical stages of the CP for industry practitioners, policymakers and anti-corruption bodies to careen their attention towards the fight against corruption.
\end{abstract}

Keywords: construction management; corruption; vulnerability; developed; developing countries.

\section{Introduction}

The construction process (CP) is reported to be complex amalgamtion of stages and processes (Albert Chan and Emmanuel Owusu 2017; Chandrashekhar Krishnan 2009). Firstly, beginning with the conception of an ideal project, carried through to the realization of that project, and includes project maintenance and the resolution of any relational or contractual disputes that may transpire during the construction process or after project completion (Hendrickson and $\mathrm{Au} 2008$ ). The construction industry 
is responsible for executing most of the tasks in the CP. However, other auxiliary industry stakeholders, such as manufacturing and banking, as well as the judicial arm of most governments, play significant roles in the CP stages (Yat et al. 2002; Buswell 2007; Owusu et al. 2017). The complexity of the construction industry is evidenced namely by: i) the diverse plethora of professionals that make up a single project team; ii) necessary relational and contractual arrangements that bind them; and iii) the coordination they require throughout the project's CP (Owusu et al. 2017). Albeit, a diverse calibre of professionals are involved in this process (e.g., architects, engineers, contractors, quantity surveyors), significant emphasis is primarily placed on the contracting team or the contractor responsible for the construction and delivery of the project. Such emphasis on the contracting team can be attributed to their high level of responsibility and hence ability to potentially distort the process of a project with corruption (Le et al. 2014b). Moreover, although complexities identified amongst the project team stakeholder are reported as a contributory factor in corruption, attribution of corruption is more commonly directed to contractors and government officials (Owusu et al. 2017).

Previously, the construction industry has been reported to be the most corrupt sector in the world (Krishnan 2010). However, a more recent report by Ivana Kottasova (2014) shows that the construction industry now comes second (behind the extraction sector) on the chart of the leading corrupt sectors globally. Corruption in this context is defined as the abuse of a project's resources, either public or private, for personal gain (Chan and Owusu 2017). To better understand the definition of corruption in the context of construction, it is necessary to identify the culture of the industry and the influencing factors upon its culture. Jian Zuo and George Zillante (2005) reported that the construction industry could be partitioned into two broad cultures, namely: project culture and organizational culture. However, a recent study by Owusu and colleagues (2017) indicates that the classifications captured under the culture of construction extend beyond the confines of project and organisational levels. The authors identified three additional important cultures, namely psychosocial, statutory and regulatory. The psychosocial construct deals with the mental, emotional, and social, well-being of the stakeholders involved and the influencing environmental conditions on both the project and organizations. The statutory and regulatory cultures define the stipulated legal and institutional principles that regulate the other constructs (i.e., project, organizational, psychosocial) of the construction cultures (Owusu et al. 
2017). All these cultures possess their respective influence and irregularities inflicting upon the likelihood of corruption experience within CP.

Moreover, as explicated later in this study, $\mathrm{CP}$ encompasses a number of different stages with myriad activities. As stated earlier, the process begins with the project conception, selection, planning through to completion and maintenance, and resolution of conflict if any. A multitude of suppositions regarding the stage related prevalence of corruption reside in the literature. For instance, reports from Transparency International (2006) and the Chartered Institute of Building (CIOB) (2013) reveal that the incidence of corrupt practices is most prevalent at the pre-construction stages. However, given the complexities in the definition of corruption in different cultures and domains, coupled with the complex nature of construction processes, there is a paucity of empirical studies examining how prone such stages are to corruption. This study, therefore, intends to investigate such likelihood of corruption at the various $\mathrm{CP}$ stages with construction cultures (i.e., project, organizational, psychosocial) in mind. Theoretically, this study intends to contribute to the body of knowledge of corruption-related studies in the field of construction management and offers a deeper understanding into the dynamic nature of $\mathrm{CP}$ stages' susceptibility to corrupt practices. It also reveals the criticality of the different forms of corruption within the stages of the CP. The findings emanating from this study provide practical information to project parties, policymakers, researchers and anti-corruption advocates about identification and criticality of the key CP stages most prone to corruption. The study intends to help by provision of practical suggestions to aid development of more focused and stringent anti-corruption tools to eliminate the prevalence of corruption identified within the CP.

\section{Literature Review}

Corruption is reported to be prevalent throughout the construction process but also occurs at all levels of stakeholder management (Krishnan 2010; Shakantu 2006; Ameyaw 2017). The entire construction process commences at the conception stage - with a conceptualization of the facility to be built (Blackburn 2012). At this stage, the concept of constructing a facility to suit a particular functional utility is established. The client or the design team offer several concepts, of which one is selected to be developed. This leads to the project selection stage, which is considered the phase where all the 
possible projects' ideas conceived at the conception stage are examined. The client or the project team settle on the project with the highest advantage, score or priority. Therefore, at this stage, every item or listing toward the commencement and development of the project are often based on either proposals or suggestions, which help facilitate the selection of a suitable project to be constructed. This is done by taking into consideration the project brief description after careful and apropos deliberation of all the other proposed projects. Moreover, the foundation for conducting this activity (i.e., selecting one out of many) is based on the project feasibility and benefits (Hendrickson and Au 2008). Whereas the feasibility concept measures the ability of the project to be successful, the benefit concept measures the positive outcomes intended to be delivered by the project (PII 2011; Harris and McCaffer 2013). Selection stage is of primary importance due to the prioritization of the numerous and diverse concepts developed at the conception stage of $\mathrm{CP}$ which may sometimes exceed the budget of the financier. Parties involved in this process may range from the project manager to an agency management team (Levy 2010). Even though the benefit of undertaking this stage process encourages transparency, some scholars and industrial experts proffer that selection stage is most prone to corrupt practice activities (Owusu et al. 2017). Catherine Stansbury and Neill Stansbury (2008) record a number of corrupt practice activities which frequently occur, or can readily occur, at this stage. For instance, selecting a project that is unnecessarily or overly-complex for the actual intended purpose, selecting a project to favour an unsuitable contractor, or predetermining a favourable contractor for a project intended to go through a competitive selection procedure.

Upon selection of the final project to be constructed, the CP transcends to the next phase, namely the planning stage (Pacific Invasive Initiative, PII 2011). This stage encapsulates the creation or development of drawing plans to guide the execution and completion of the proposed project. Planning stage delineates the modus operandi of each project team member by defining specific stakeholder responsibilities. Project planning is often facilitated by computer applications and tools such as the Gantt chart or Microsoft Office Project (Wilson 2003; Chudley and Greeno 2013). Ameyaw and colleagues portions of the project to favour some suppliers or contractors on the basis of relational attachments rather than necessary qualification. Moreover, as noted at the project selection stage, team members responsible for the planning process may incorporate redundant work items just to create room 
for exploitation of a project's resources during the project execution phase (Owusu et al. 2017; Locatelli et al. 2016; Sohail and Cavil 2008). The number of activities carried out at selection stages increase susceptibility to corrupt practices, which according to Stansbury and Stansbury (2008), leads to professional negligence - a primary form of corrupt practice at this stage. At the design stage (DS) the project manager expands on the items planned at the preceding stage and details the organization, management, governance and the design of the project. At this stage all project plans, specifications and requirements are integrated to develop a full-blown 3D model or 2D set of drawings (either paperbased or computerized), serving as a blueprint for the execution phase (Hendrickson and Au 2008). Corrupt practices often noted at the design stage include [but are not limited to]: i) exaggeration of a project's design and price to upsurge possible fraudulent remuneration during the project's execution; ii) manipulating the design of the project to favor specific contractors, suppliers and other team players; iii) giving facilitation payments to government officials for a satisfactory environmental impact endorsement; or iv) changing project's timing (Chan and Owusu 2017; Brown and Loosemore 2015; Stansbury and Stansbury 2008). Aforementioned pre-contract activities tend to manipulate the process with favouritism, bribery and other forms of corrupt activities. Inasmuch as all these CP stages are identified to be vulnerable to corrupt practices, the situation is reported to be worse at the latter stages of the construction process. They are the pre-qualification and tendering stage, the contract signing stage, and the project execution stage. Some of the identified corrupt practices include: i) tender rigging, ii) price fixing, iii) obtaining a quotation only to compare price, and iv) submission of false quotations (Owusu et al. 2017; Le et al. 2014; Chan and Owusu 2017).

Other prominent examples include: i) false or over-invoicing for the supply of either inferior materials or less equipment; ii) inflating claim amounts especially with regards to variation; iii) concealing defects; iv) giving a false hope or assurance of contract payments to be made; v) facilitation payments and other forms or acts of bribery to overlook substandard executed works, and many others (Owusu et. al. 2017; Zhang et al. 2016; Shan et al. 2016). This is the stage where actual construction works are undertaken, or the plans and designs that were developed at the conception/design stage are undertaken, this stage being very vulnerable to high incidences of corrupt practices. The next critical project maintenance stage is where periodic checkups of the constructed condition or quality of an 
existing building are conducted to be compared against the required project brief and client requirements. This is done in order to correct any defects and keep the building in a sound shape after completion (Watts 2016; Hendrickson and Au 2008). Building maintenance is therefore conducted from time to time to reveal any defects that may render the building unsafe or unhealthy to occupy. However, this stage is similarly prone to corrupt practices. Some of the noted examples at this stage include : i) dishonesty or overpriced procured items for the maintenance works; ii) executing substandard maintenance works; and iii) providing false quotations of purchased items, among other practices (Kenny 2009; Stansbury and Stansbury 2008). The last stage to be considered is the dispute resolution stage - evolving purely as a result of disagreement among contracting parties (Seifert 2005). Contractual or project disputes are not common to every project, however once they happen, they may contribute to the incidence of corruption. Some corrupt practices identified or likely to occur at this stage have previously been discussed in the literature; these corrupt practices include: i) the submission of false supporting documents; ii) disproportionate billing by arbitrators or ruling parties; iii) bribery of witnesses to provide false witness evidence or expert evidence, among many others (Harmon 2003; Menkel-Meadow, 1996).

In addition, other thematic leitmotifs explored in literature on this subject include: i) different forms of corrupt practices prevalent at the different stages of the process; ii) common causes of the identified forms of corruption; iii) corruption risk indicators; iv) anti-corruption measures (ACMs) developed to eliminate the identified forms of corruption and lastly, iv) barriers to effective implementation of ACMs (Shan et al. 2016; Tabish and Jha 2011; Le et al. 2014; Bowen et al. 2012; De Jong et al.2009; Krishnan 2009; Stansbury 2009; Locatelli et al. 2016) .

Florida (2010) first pointed in his article entitled: "What Makes Countries Corrupt?", that corruption does not necessarily happen in a vacuum. It takes corrupt parties to initiate the process of corruption. Boyd and Padilla (2009) pointed out that there are three categories within which a corrupt party may fall, namely: i) demand party (one who calls for or initiates the corrupt process); ii) supply party (one who delivers or responds to the demands made by the demand side); and iii) condoning party (one who acts as a bystander with little to no care about the incidence of a corruption). Therefore, depending on a specific project and parties involved, these three categories are inextricably linked to 
any of the project parties (i.e., contractors, government officials, suppliers) who aim to distort CP for illegitimate personal gains. In a similar vein, albeit some factors may render projects more susceptible to corruption, the parties involved in a construction project are often unequivocally responsible for nurturing various forms of corruption alongside the associated causal factors (Owusu et al. 2017). In addition to bribery (most frequent form of corruption) other commonly referred fraudulent practices include: collusion, patronage; ghosting; discriminatory practices such as cronyism, nepotism, favouritism; and extortionary practices such as clientelism, blackmail, and coercion (Le et al. 2014; Willar et al. 2016; Brown, J., and Loosemore 2015; Sichombo et al. 2009), to name but a few reported from past studies. A comprehensive list of the noted forms of corruption in the construction industry have been comprehensively reported in a recent review study conducted by Albert Chan and Owusu (2017).

However, according to Owusu and colleagues (2017), such forms of corruption crop up or evolve as a result of myriad causal factors, which include but are not limited to: statutory-specific, project-specific, regulatory-specific, psychosocial-specific and institutional specific causes. Emanating from fierce competition as seen during the tendering process, the CP is doggedly corrupted by greed, substandard professional ethical conduct, government/political influences and overclose stakeholder relationships (Zhang et al. 2016; Tabish and Jha 2011; Le et al., 2014). Lastly, scholars have recorded practical strategic mechanisms to expurgate corrupt practices in construction projects using frameworks and toolkits namely by: raising public awareness about corruption, conducting stringent contract monitoring, performing rigorous supervision and auditing, and establishing a high standard accountability mechanism among several others (Tabish and Jha 2012; Zou 2006; de Jong et al. 2009; Søreide 2002). However, this study discusses the criticality of the various forms of corruption at the respective stages of the $\mathrm{CP}$ as well as the susceptibility of these stages to corruption.

\section{Research Methodology}

\section{Structured Survey}


To begin, an expert survey was conducted using a questionnaire. The questionnaire survey technique has been widely used to solicit professional views on subjects within the domain of construction management-related research (Tan 2011; Fellows and Liu 2015; Shan et al. 2017). Similarly, this study used a questionnaire as an instrument to explore the views of professionals involved in CP. This method was adopted as a means to reliably gather information subject experts at a relatively inexpensive cost (Hoxley 2008; Ameyaw et al. 2017). The questionnaire was designed to gather the experts' views on the susceptibility of the construction stages to corruption as well as the critical forms of corruption prevalent at each stage. The questionnaire was structured in four primary sections. The first section presented the overall aim and objectives of the study and assurance of the respondents' anonymity and data confidentiality. Second section was designed to gather the background information from respondents including: i) professional affiliation, ii) working experience, and iii) geographical region. Section three solicited experts' views on the susceptibility of the construction phases to corruption using a five-point Likert rating scale (1= not vulnerable, $2=$ less vulnerable, $3=$ neutral, $4=$ vulnerable, $5=$ extremely vulnerable). Subsequent Likert scaling is predominantly adopted in $\mathrm{CM}$ research to facilitate the rating of relative importance of factors considered for a study that is based on expert views (Ameyaw and Chan 2015; Shan et al.2017). The fourth and final section sought to gather experts' opinions on the most pressing corruption form $(\mathrm{CF})$ at the respective stages of the $\mathrm{CP}$ using the constructs developed by Chan and Owusu (2017) (i.e., 1=bribery, $2=$ fraud, $3=$ collusion, 4=extortion and 5=discrimination). Prior to the expert survey, a pilot study was conducted to examine the rationality, appropriateness, technicality, comprehensiveness, relevance and language of the questionnaire. The questionnaire was reviewed by eight experts, comprised of five scholars (three professors and two senior lecturers) and three top tier industrial experts from world-renowned institutions including the World Bank, the United Nations and the Global Infrastructure Anti-Corruption Coalition (GIACC). The questionnaire was revised and completed based on the comments received from scholars and experts and disseminated to carefully selected experts (both academics and practitioners) via email, (between May 2017 to November 2017). These experts were identified by contribution to the body of knowledge on corruption and involvement in the construction supply chain and other infrastructure projects. It can, therefore, be justified that the purposive sampling (a non- 
probabilistic sampling technique) was adopted to select the respondents for the study. This selection approach was employed to obtain quality respondents and guarantee balanced, credible and reliable feedback (Ameyaw et al. 2017). In order to encourage respondents' participation, the respondents were assured of their anonymity and confidentiality (Darko et al. 2017; Li et al. 2011). Over 300 questionnaires were distributed, with 62 retrieved responses. However, only 44 responses were deemed valid for further analysis due to the incomplete or unanswered questionnaires. The respondents range from 18 different countries with a 50/50 split between developed and developing countries (as shown in Fig.1). It must be emphasized that the authors continued to solicit data on other constructs of the research project (under which this topic was investigated) even though the solicitation of the responses for this study was stopped.

Contextual sensitivity of the topic has rendered an unwillingness of some respondents to fully disclose their full opinion on the subject matter, and has ostensibly led difficulty to obtain a larger sample size of data (Ameyaw 2017; Brown and Loosemore 2015). Moreover, other potential respondents turned down requests to be involved in a study of this nature in order to protect their identity to prevent reprisal. Therefore, similar to the study of Ameyaw et al. (2017), this study stipulated some ethical measures to address any such concerns. The authors assured respondents that their identity was protected and that responses provided would be used solely for academic purposes and would also remain confidential. The ethical control procedures stipulated ensured a favourable sample size as compared with that of past studies; for instance, studies conducted by Ameyaw et al. (2017), Brown and Loosemore (2015) and Charles Vee and Martin Skitmore (2003) on the same subject of corruption in CM were based on 35, 23 and 31 responses, respectively, whereas the results of Tabish and Jha (2011) were based on six respondents. Therefore the sample size obtained in this study was deemed adequate to extract significant findings. Moreover, even though the sample size remained relatively small, data analysis could still be carried out due to the fulfilment of the central limit theory of 30 responses (Chan et al. 2017; Hwang et al. 2015; Lyman Ott and Michael Longnecker 2015). The profiles of the respondents are presented in table 2.

\section{Data Analysis}




\section{Data Normality Test}

Tae Kim (2015) indicated that many statistical tests require data to be normally distributed. This study, therefore, conducted the data normality test to identify the distribution pattern of the data. The ShapiroWilk test (SWT) was used to reveal the data distribution. SWT is commonly employed and recommended as an appropriate tool to determine the distribution pattern of any given dataset (Gel et al. 2007; Shan et al. 2017; Ott and Longnecker, 2015). The null hypothesis of the SWT states that "the population was normally distributed". Therefore, if the alpha $(\alpha)$ value generated is less than the actual significance level (i.e., 0.05), a conclusion can be drawn that the dataset is non-normally distributed and subsequently the null hypothesis is rejected. Following similar corruption related studies as well as other CM based research such as Amos Darko and Albert Chan (2017) and Shan and colleagues (2017), the actual significance level chosen was 0.05 and the test was conducted using SPSS statistics.

\section{Determination of Cronbach's Alpha and Mean statistics}

The data was analyzed using the SPSS v. 23 statistical package. Firstly, the data was statistically tested to determine the scale of reliability and credibility for the topic under investigation. The Cronbach's Alpha (CA) tool was employed to perform this operation. The CA method remains one of the most popular and widely used methods for measuring scales' of reliability (Ameyaw and Chan 2015). It determines the internal consistency or average correlation among variables in a given questionnaire to examine the reliability of the questionnaire. The value of the CA coefficient $(\alpha)$ ranges from 0 to 1 and can be used to describe the reliability of variables deduced from questionnaires or dichotomous and multipoint structured scales (Chan et al. 2017; Reynaldo Santos 1999). The closer the value of $\alpha$ is to 1 , the more reliable the adopted measurement scale. Simply put, a high $\alpha$ value indicates high reliability and vice versa. Nunnally (1978) presented a rule of thumb for the threshold of the reliability index. According to the author, in order to justify the reliability of the scale adopted, the $\alpha$ value should be no less than 0.7. SPSS 23.0 statistical package was specifically employed to calculate the value of $\alpha$ for this dataset. The value obtained was 0.935 which indicated a very high degree of reliability. The dataset was therefore regarded for further analysis (Chan et al. 2017). 
Moreover, despite a relatively low number of responses, the experts were assigned to one of two groups based on their geographical and economic backgrounds (i.e., developed and developing countries). The alpha $(\alpha)$ values for both were estimated to be 0.961 and 0.788 , which render the results from each expert group credible, reliable and valid for further discussions and analysis. These two categorizations were made to examine the proposition of the significant differences or disparities that exist between these two regions regarding corruption pervasiveness and control in the supply chain of the construction process. Hence, the relevance of this study is to empirically test the aforementioned knowledge gap in the field of CM research. To determine the relative importance or the level of vulnerability of each phase of the CP to corruption, the mean score (MS) approach, widely espoused of in CM-based research and other corruption-related studies, was adopted to facilitate these estimations. The mean index for each stage revealed the degree of susceptibility for the respective stages of the CP as well as the criticality of the corruption forms within the CP. Moreover, in order to determine the relative importance of each phase of the $\mathrm{CP}$, the statistical t-test of the mean values was adopted at a test value of 3.5 against the significance level of 0.05 .

\section{Contextual comparisons}

The Mann-Whitney U (MWU) test was adopted to examine the degree of relationship of variable rankings between two groups (i.e., developed and the developing countries) regarding the stages involved in the CP's susceptibility to corruption from the perspective of the experts' geographical context (Darko et al. 2017; Chan et al. 2009). The essence of this test was to determine the significant differences in between the two contexts regarding CP stage's susceptibility to corruption. The MWU test was therefore regarded as suitable for measuring the significant difference between the two independent group responses on a similar question (i.e., the degree of vulnerability each $\mathrm{CP}$ stage is to the incidence of corrupt practices). According to Lam et al. (2015), there is no requirement for prior postulation on the distribution of data during the application of this method. Moreover, the sample sizes of the groups involved can be varied or wide-ranging (Chan et al. 2017). The MWU test converts ratings provided by the respondents on individual variables to different ranks across the two groups involved (Osei-Kyei and Chan 2015). Subsequently, MWU reveals whether the ranks established by the two 
groups possess significant differences or not. In the application of $\mathrm{MWU}$, the $\mathrm{H}_{0}$ signifies that 'there is no significant difference in the variable ranks among the two groups.' As a result, $\mathrm{H}_{0}$ is rejected if the MWU value extends beyond its critical value at a significance level less than or equal to 0.05 ( $\mathrm{p} \leq 0.05)$.

Table 4 presents the results obtained from the MWU test with the demonstration of the $\mathrm{z}$ values obtained for the vulnerability level of each of the eleven CP stages (i.e., C1-C11) with their respective $\mathrm{p}$-values. For instance, the $\mathrm{z}$ value for project selection stage is -1.242 with a significance level of $\mathrm{p}=0.214$. As presented in table 4 , apart from the stages ' $\mathrm{C} 1$ ' $(\mathrm{p}=0.604),{ }^{\prime} \mathrm{C} 2$ ' $(\mathrm{p}=0.214),{ }^{\prime} \mathrm{C} 3$ ' $(\mathrm{p}=0.368)$ and ' $\mathrm{C} 5$ ' $(\mathrm{p}=0.157)$, the $\mathrm{p}$-values for all the remaining stages are less than 0.05 . This means that aprt from these four stages as stated, the U test results for all the remaining stages show high significance, indicating statistically significant differences among the ranks of seven out of eleven stages as expressed by the two independent groups. The findings confirm the propositions stipulated from the literature on the differences between developing and developed countries regarding the pervasiveness of corruption and the measures for extirpating their incidence and effects in construction works. Moreover, these findings confirm that CP stages in the developing context are highly vulnerable as opposed to the expert views held in developed regions. That is, whereas experts from the developing countries agree on the high susceptibility of some of the CP stages to corruption, experts from the developed context share a collective view that all the CP stages are less vulnerable to the incidence of corrupt practices, even though their shared views do not suggest or stipulate an absolute absence of corrupt practices in the supply chain of construction works. These views are presented in figures 4 and 5 .

\section{Internal Consistency}

The Chi-square test and Kendall's coefficient of concordance (w) are the two most frequently employed methods to examine the overall concurrence among ranking sets of non-normally distributed data (Lam et al. 2015). It is, therefore, appropriate to regard it as a non-parametric test. The Chi-square test was used to justify the respondents' levels of concordance since the number of critical variables examined was set to be more than seven (Wong et al. 2016). This study examined eleven critical stages. Regarding the application of the Chi-square test, the calculated Chi-square value was compared with the critical 
Chi-square distribution at the allowable significance level of 0.05 under the required degree of freedom (Df). The results are presented in Table 2. From the results, the level of significance satisfied the stipulated conditions. That is, referring to the values of the actual Chi-Square distribution table at the significance level (0.05) under the Df of 10; the actual Chi-square value is set at 18.307. However, the results indicate that the calculated Chi-square which is 46.039 , was greater than the critical stipulated value, 18.307 as presented in table 2 . The results, therefore, confimr the comon disposition amongst the views of the various experts on the suggested rankings of the CP stages' susceptibility to corruption.

\section{Stage by stage comparison}

Analogous to the study of Hwang and colleagues (2017) and Shan and colleagues (2017), this study conducted a detailed stage-by-stage comparison to identify the most critical CP stages vulnerable to the incidence of corrupt practices as reported by the respondents. Two statistical techniques are often considered to perform the test based on the data distribution. They are the paired t-test (parametric test) and the Wilcoxon's signed rank test (non-parametric). Whereas the parametric test requires the data to be tested to be normally distributed, the alternative Wilcoxon's signed rank test is employed to compare matched variables with no assumptions of the nature of data distribution. Simply put there is no requirement for the data to be normally distributed (Shan et al. 2017). Therefore, due to the nonnormally distributed nature of the data obtained in this study, the Wilcoxon's signed rank test was employed to perform the variable (stage-by-stage) comparisons.

\section{[PLEASE, INSERT TABLE 1 HERE]}

\section{Survey Results}

A total number of 44 responses were considered for further analysis. Many of the responses emanated from researchers with past industrial experience, contractors and engineers constituting over $85 \%$. Over $60 \%$ of the respondents had more than 11 years of working experience or involvement in the construction supply chain. Coupled with such diverse backgrounds an overall high CA value of 0.935 was obtained, confirming the results as highly reliable and credible. The discussions are therefore made with respect to the two types of regions identified. However, since the respondents from the developed 
countries exceeded the responses obtained from the developing countries, it was considered that amalgamating the responses would potentially skew the results towards the responses from the developed context. Analysis and discussions are therefore made regarding the regions highlighted. Figure 1 represents the countries of the respondents involved in the expert survey. With the maximum number of respondents from the Hong Kong Special Administrative Region and Australia, there is a relative level of consensus among experts from developed countries and developing countries regarding the rankings of the stages as indicated by Kendall's coefficient of concordance (w) significance level and the corresponding Chi-square value.

[PLEASE, INSERT FIGURE 1 HERE]

\section{Results and Discussions}

\section{Corruption prevalence and control}

Broad consensus, in both the extant literature and institutional reports points tothe disparities of corruption control and pervasiveness among developing and developed countries (Owusu et al. 2017). Whereas most developed countries are reported to have stringent and effective mechanisms to deal with corrupt practices and their attributes in various aspects, such is the opposite case in developing countries. However, albeit the statistics capture a vignette of general views on corruption, individual responses regarding the pervasiveness and control of corruption from the perspective of the construction sectors within these two regions is lacking. This study contributed to bridging the identified knowledge gap on the disparity between developing and developed countries with corruption in $\mathrm{CP}$ stages (See Figure 2).

\section{[PLEASE, INSERT FIGURE 2 HERE]}

Figure 2 represents the mean index for corruption pervasiveness and control between the two regions.

The statistics presented in Fig. 2 forms the basis for the discussions in the subsequent sections, as it indicates two divergent views on both constructs from the two classes of experts involved in the survey. 
While experts from the developed countries overall showed less prevalence of corrupt activities in CP coupled with higher levels of control measures, experts of the developed countries share a dissimilar view in both constructs. Table 3 presents the general overview of the responses from experts in both regions on the susceptibility of the $\mathrm{CP}$ stages to corruption and their respective scores. The table highlights the highly ranked stages in each case using the mean index ranking as well as the significant p-value for each respective stage.

[PLEASE, INSERT TABLE 2 HERE]

\section{[PLEASE, INSERT TABLE 3 HERE]}

Table 2 presents the mean statistic, standard deviations, significance level and the rank of each stage of $\mathrm{CP}$ as expressed by the two different groups concerning their views on the susceptibility of the construction stages to corruption. The overall assessment of the responses was conducted to estimate the general view of the CP stages' susceptibility (found in the overall scores column). Albeit the results exhibited a degree of skewness in the overall MS towards that of the developed countries, this is likely due to large disparities in the ratio of the developed to that of the developing (about 1.6:1). Results point to the criticality of a number of stages of $\mathrm{CP}$ as exporessed by the developing conuntries. The mean scores for the stages of CP in the developed countries were relatively lower, indicating 'less vulnerable' for all CP stages overall. Hence, such disparity in the results from the developed countries respondents have greatly influenced the overall scales. Therefore, the overall mean scores indicate that circa half of the CP stages are deemed less vulnerable to corrupt practices whilst the other half indicate neutral points for the stages' susceptibility to corrupt practices. Overall, the experts indicated that likelihood of susceptibility is descending order in the following CP stages: project execution; prequalification stage; service delivery; and dispute resolution stages. The extant literature has already recognized these phases as most susceptible to corrupt incidents occur with the exception of the dispute resolution stage, which has not been previously discussed thoroughly in the literature. 
Individual responses from experts in developed countries, demonstrated overall consensus that all CP stages are relatively less vulnerable to the incidence of corrupt practices. With the highest mean being 2.41 , both the pre-qualification and tendering stages and project execution stage were identified to be most susceptible to the practices of corruption. Both had a similar mean score, which is expressed explicitly as less vulnerable stages. Moreover, even though all the stages were identified to be less vulnerable to corruption, none of these stages were expressed to be completely devoid from corruption occurring at each stage. Figures 3 and 4 best illustrate this point, where respondents indicated the most pressing forms of corruption identified for each stage. Contrary to developing countries, results obtained from developed countries depicted high significance levels among all the variables (stages of the construction process) with the significant p-value of each stage less than or equal to 0.05 . Conversly, upon further examination of results obtained from the developing countries', a number of divergences were identified in comparison to results from developed countries. Despite having identified that the mean values measuring levels of vulnerability were greater in developing countries, four out of the 11 distinct phases were regarded as significant. The project execution stage holding the highest mean score of 3.94 with a significant p-value of 0.001. Pre-qualification and tender stages followed with a mean score of 3.71, service delivery (score of 3.53) and dispute resolution stages (score of 3.53) were ranked fourth and fifth. Moreover, the stages regarded as significant with relatively lower mean scores were conception and planning stages.

Table 3 represents the Mann Whitney U (MWU) test as previously alluded to. As indicated in the MWU test results, there are significant disparities between developing countries and the developed countries regarding corruption pervasiveness and control. Whereas developed countries have stricter measures in place to control corruption, countries from the developing world dogged by corruption amidst development and enforcement of innovative and pragmatic measures to tackle corruption (Owusu et al. 2017). Ineffectiveness of such control mechanisms often tend to create enough room for corrupt practices to thrive with ease throughout the CP process (Bowen et al. 2012; Tabish and Jha 2011). In table 3, considerable differences were identified in 7 out of 11 stages between the developing and the developed countries, capturing more than half of the entire CP stages. These include: i) inspection stage, ii) pre-qualification and tender stage, iii) through to the dispute resolution stage. 
Moreover such findings show that all the identified stages vary significantly regarding their levels of susceptibility to corruption. Simply put, the CP stages of developing countries are more plagued with corrupt practices as compared to that of the developed countries.

Lastly, the overall top three stages most susceptible to corruption are: i) project execution stage (CP8), ii) pre-qualification and tender stage (CP6), and iii) service delivery stage (CP9). Results from the Wilcoxon's signed rank test (as presented in table 4) show that, comparatively, the assessment for CP8 was statistically higher than that for as many as seven other stages: CP10, CP7, CP4, CP2, CP5, $\mathrm{CP} 3$ and $\mathrm{CP} 1$. This indicates the findings from this study support the observations alluded to by Tabish and Jha (2011) and Le and colleagues (2014), project execution stage being quintessentially most susceptible to corruption.

[PLEASE, INSERT TABLE 4 HERE]

\section{Assessment of CFs throughout the CP stages}

Respondents were asked to identify most pressing forms of corruption prevalent at each phase of CP. Adopting the constructs from the study of Chan and Owusu (2017), the constructs identified are: bribery acts, fraudulent acts, collusive acts, discriminatory acts and extortionary acts. Using a rating scale of $0-5$, where 0 represents extremely uncritical, $1=$ uncritical, $2=$ somewhat uncritical, $3=$ somewhat critical, $4=$ critical and $5=$ extremely critical, figures 3 and 4 present the CFs pervasiveness in each stage of the CP of both the developed and the developing countries.

\section{[PLEASE, INSERT FIGURE 3 HERE]}

Results from the developed countries' respondents indicate that even though the phases of construction are less vulnerable to incidents of corruption, marginal levels of agreement were inidcated on pervasiveness of the identified forms of corruption being prevalent throughout the $\mathrm{CP}$ phases with exception to extortionary acts showing less prevalence. However, whereas some forms are highly prevalent at specific stages, others show a very minute degree of occurrence. The stage by stage analysis shown in figure 3 reflects the dynamic frequency of the incidence of corrupt practices within the $\mathrm{CP}$ of 
the developed countries. Both project conception and project selection stages show the highest levels of bribery and collusive practices respectively, with project execution and maintenance demonstrating a high level of fraudulent practices. Discriminatory acts were identified to be prevalent at the design and prequalification stages, and even though extortionary acts were identified to have a low level of pervasiveness through the $\mathrm{CP}$, the highest score occurred at the project execution stage.

Moreover, there is a dominant and a dogged persistence of bribery, collusion and fraudulent acts throughout the process unlike the case of the developing countries where almost all the stages were identified to be debauched by high concentration of bribery acts. The leading three vulnerable stages are briefly elucidated upon in the following section regarding the most pressing forms of corruption exhibited. In the case of the developing countries' rankings, the leading vulnerable stages are the prequalification stage; tender stage; project execution stage and dispute resolution stage. This reemphasizes the findings in the studies of Stansbury and Stansbury (2008), Tabish and Jha (2011) and Ling and colleagues (2014) which have identified some examples of corrupt practices in both the prequalification and tender phase and the project execution phase. Interestingly, the frequently mentioned dispute resolution stage was one of the top three most susceptible stages to corruption. Though little existing research has addressed the issue of corruption at the dispute resolution stage, it seems likely that there is a need for more empirical research on corruption focussed on this stage of the CP.

In both project execution and dispute resolution phases, the most pressing forms of corrupt practices identified were fraudulent and collusive acts respectively. Moreover, three different forms were identified at the pre-qualification and tender stages with the same score point: discriminatory, collusive and fraudulent practices. Remarkably, the most frequently mentioned form of corruption bribery -- obtained a relatively low score at all three leading stages as expressed by the respondents from the developed countries. However, it is obvious that many efforts in the development of anticorruption measures in the fight against bribery have been very influential over the past decades (Le et al. 2014). Such results seem to imply that bribery has not received as wide attention/monitoring. Future studies with a more specific focus in terms of context can contribute to deeper inquiry into such subjects. The summary of the CFs criticality in both developed and the developing countries' CP process are presented in figures 2 and 3 respectively. 


\section{[PLEASE, INSERT FIGURE 4 HERE]}

Unlike the findings of the developed countries, respondents from the developing countries indicated that the identified forms of corruption are not very prevalent at the project conception stage. Moreover, not all the forms are prevalent in all the stages. The respondents are of the view that the planning and dispute resolution stages of construction projects are less likely to be polluted with extortionary acts, and both design and pre-qualification and tender stages recorded no form of fraudulent practices. Also, other stages such as project execution and maintenance and service delivery, respectively, recorded no traits of discriminatory and collusive acts. However, a sturdy rise of bribery acts were recorded from the planning stage peaking at the project execution stage recording the highest level of corrupt acts. Moreover, at the pre-qualification stage, bribery act is seen as a dominating form of corruption through to the dispute resolution stage.

Regarding stage by stage analysis, the critical stages identified by the respondents by their respective means include: project execution, pre-qualification and tender, service delivery and dispute resolution stages. The results present a common consensus that the project execution phase is the most susceptible of stages to corruption in the developing countries. The respondents similarly indicated that this stage records the highest form of bribery practices such as: kickbacks, solicitation, facilitation payments and lobbying (Chan and Owusu 2017). However, other CFs such as collusive, fraudulent and discriminatory practices recorded relatively lower scores and no scores with regards to extortionary acts at this stage. At pre-qualification and tendering stages, approximated mean scores indicate 'vulnerable', this stage as largely agreed upon by the respondents is the second most vulnerable stage of the construction process. Bribery acts similarly dominate this stage of $\mathrm{CP}$ followed by collusive practice, and discriminatory and extortionary acts. Albeit the construct of fraudulent acts recorded no score at this stage, collusive practices such as cartels, price fixing and bid-rigging also variants of fraudulent acts were identified to be prevalent at this stage of CP. Both service delivery and the dispute resolution stages also recorded bribery to be the most prevalent form of corruption with collusive and extortionary practices having no scores at the two phases respectively. However, the respondents agree that other 
forms of corrupt practices such as discriminatory and fraudulent practices are common at both stages. And lastly, whereas extortionary acts are common at the service delivery phase, collusive practices are as well common at the dispute resolution phase as indicated by the respondents from the developing world.

Stansbury and Stansbury (2008) highlighted a number of identified corrupt practices throughout the construction process. The authors revealed the prevalence of such forms at the pre-qualification and bidding stages of the execution of projects and the times of resolving contractual or other construction disputes. The noted CFs included price-fixing (identical to cartels) where a group of contractors tendering for a similar project clandestinely concur to manipulate the market by sharing the opportunities (contracts) available with the specified market among themselves. For instance, a class of contractors competing for a project may conspire to settle beforehand on which of them wins the project at hand. A different contractor will, therefore, be selected for the second project. Thus, they run shifts per the number of projects they tender for. This practice is, however, kept confidential from the owners of the projects. Other pre-tender manipulations may involve the consultants or engineers appointed by project owners who also conspire with potential contractors in diverse distorted means to award a contract to a corrupt bidder. The forms may include discriminatory acts such as cronyism and nepotism, bribery acts such as solicitations, influence peddling, kickbacks and many others (Sohail and Cavill 2008; Adams 1997; Bowen et al. 2012, Stansbury 2009, TI 2018). These forms may have countless manifestations. For instance, consultants may demand a bribe from a specific bidder or demonstrate favouritism in order to award a contract to a comparatively less qualified bidder and in other instances, a bidder may approach project consultant(s) to biasedly adjudicate the contract to his favour. Others may demand disclosure of project information prior to the preparation and submission of tender documents for a competative advantage during the bid evaluation stage (Owusu et al. 2017). During the project execution stage, some identified forms, or examples include false invoicing, overpricing of supplied materials (sometimes inferior) or equipment, and concealing identified defects without rectification during interim inspections of ongoing works (Stansbury and Stansbury 2008; Tabish and Jha 2017). Lastly, the dispute resolution stage was identified by the respondents from the developing 
countries to be another key stage susceptible to incidence of corrupt practices even though the opposite reflects the condition of the developed context. Thus, the MWU test confirms the wide disparities between the responses of the experts from the two contexts regarding the vulnerability of the dispute resolution stage (if any). According to Stansbury and Stansbury (2008), some of the noted practices include submission of false testimonial (witness evidence), exorbitant billing by arbitrators, umpires or lawyers, bribing or blackmailing witnesses among other forms. There is, therefore, the need to develop specific and dynamic anti-corruption measures and frameworks targeted at dealing with the specificity and the criticality of CFs and their associated causal factors at the different stages of the construction process.

\section{Limitation and Future Research}

This empirical analysis presents a general overview of the susceptibility of CP stages to corruption in both the developed and the developing countries. First, since the paper commenced the discussion in a broader context (i.e., developing and developed countries), the results cannot be generalized for every specific country that falls under these two dichotomous geographical groups. It must, therefore, be emphasized that inasmuch as the discussions were made based on the overall responses retrieved, the discussions regarding the disparities of the two contexts are conducted for descriptive purposes. Thus, due to the low sample sizes regarding each context, any reference made to the findings on the contextual explications in this study should be done with this limitation duly presented to deter any clue of statement misrepresentation or ambiguity. This as well accounts for the non-generalization of the results and therefore encourages similar works to be conducted in more defined and specific contexts using this study as a foundation. Also, the page and space limit would not allow for the discussion of individual countries involved. Authors, therefore, recommend that researchers (academic or industrial), from specific countries, investigate to identify the specific levels of the susceptibility of each of the CP stages regarding their countries.

In addition, five stages of $\mathrm{CP}$ were identified as vulnerable for developing countries, albeit this may vary from country to country, and this is same for the case of the developed countries. The authors, therefore, suggest that future research studies be carried out in a more specific context, that is, country 
by country or institution by institution to identify vulnerability to corruption at $\mathrm{CP}$ stages in the specific context that is being investigated. More specificity in such results can better inform the areas requiring immediate attention in the fight against corruption or much required anti-corruption measures. After the identification of vulnerable stages, more detailed research exploration can be made into the myriad constructs of corruption which include: i) identification of respective forms of corruption; ii) causes and risk indicators of corruption; and iii) barriers hindering effective development and application of anticorruption measures. Three most vulnerable stages identified in the findings of both developing and developed countries were: i) pre-qualification and tender phase; ii) project execution phase; and iii) dispute resolution phase. Yet, dispute resolution stage has received a lack of attention regarding corruption control specifically in construction project management. There is the need to channel efforts to determine variants of corruption, causes and the risk indicators related to this specific phase to come up with needed anti-corruption measures to curb corruption at this stage.

\section{Conclusion}

This study presents empirical research on susceptibility of the CP stages to corruption as well as the prevalence of the corruption forms at these respective stages. The exploration and identification of the CP stages most susceptible to corruption are very useful not only for informational purposes but also for the development and implementation of pragmatic and strategic anti-corruption measures aimed at dealing with the prevalence of corruption in the construction supply chain. The study identified eleven distinct stages involved in the construction process. An international survey offers experts views from both developing and developed countries to determine the levels of vulnerability of each stage to the prevalence of corruption. In addressing the two aims, the authors identified a number of disparities on the subject of corruption between the geographical context which confirms the propositions raised in the literature. Even though both jurisdictions demonstrated less agreement on the pervasiveness of corruption, comparative difference lies in the number of stages which indicated high vulnerability in both developed and developing regions. That is, whereas all the stages of $\mathrm{CP}$ in the developed countries are less vulnerable to corruption, some stages of $\mathrm{CP}$ in the context of the developing world were regarded to be vulnerable to the incidence of corruption. Beginning with the stage with the highest mean 
values to the least, these four stages comprise of: project execution, pre-qualification and tendering, service delivery, and dispute resolution stage.

Moreover, the MWU test established significant differences in the rankings of the stages between the two expert groups. The results indicated significant difference among seven out of eleven stages, validating the differences of corruption prevalence and control in both the developed and the developing world. Also, in identifying the critical forms of corruption prevalent at each stage, the experts from the two regions reported a significant levels of diversity on this question. Whereas bribery, collusion, and fraudulent practices were reported to commonly occur throughout the $\mathrm{CP}$ in developed countries, bribery is seen to be the dominant form of corruption for developing countries. Lastly, even though the conception stages of both the developed and developing countries recorded either the least (or close to the least) levels of vulnerability, experts from the developed countries view that different forms of corruption -- especially bribery, collusion, fraudulent and discriminatory practices -- are the leading corruption forms when the projects requirements are defined. Since this study presented an empirical overview of the dynamic nature of corruption in the CP stages, authors recommend that future research be carried out in specific contexts (i.e. countries and institutions) to identify a real case studies in different countries and institutions.

\section{Conflict of interest}

The authors confirm that the authors of this paper have no conflicts of interest.

\section{Acknowledgement}

This paper forms part of a research project entitled "Dynamic Evaluation of Corruption in Public Infrastructure Procurement: A Comparative Study of Emerging and Established Economies," from which other deliverables have been produced with different objectives but sharing some levels of commonalities. We express our sincere gratitude to the Research Grants Council (RGC) of Hong Kong and to the Hong Kong Polytechnic University for funding this study. We are grateful to the industrial and academic experts involved in this study for the invaluable input, support and motivations (for both 
pilot study and the main survey). Lastly, the authors are extremely grateful to all the anonymous reviewers for providing constructive comments to enhance the quality of this paper.

\section{References}

Ameyaw, E. E., Pärn, E., Chan, A. P., Owusu-Manu, D. G., Edwards, D. J., \& Darko, A. (2017). Corrupt Practices in the Construction Industry: Survey of Ghanaian Experience. Journal of Management in Engineering, doi: 10.1061/(ASCE)ME.1943-5479.0000555

Blackburn, T. (2012). A Project Lifecycle and the Construction Process - Seven Stages from Conception to Demolition. Available at: https://pdhonline.com/courses/p155/p155content.pdf. Accessed on 25 August 2017)

Bowen, P. A., Edwards, P. J., \& Cattell, K. (2012). Corruption in the South African construction industry: A thematic analysis of verbatim comments from survey participants. Construction Management and Economics, 30(10), 885-901.

Brown, J., \& Loosemore, M. (2015). Behavioural factors influencing corrupt action in the Australian construction industry. Engineering, Construction and Architectural Management, 22(4), 372389.

Chattered Institute of Building CIOB, (2013). A Report Exploring Corruption in the UK Construction Industry. The Chartered Institute of Building. https://www.ciob.org/sites/default/files/CIOB\%20research\%20$\% 20$ Corruption\%20in\%20the\%20UK\%20Construction\%20Industry\%20September\%202013. pdf. Accessed 16 December 2017.

Chan, A. P., \& Owusu, E. K. (2017). Corruption Forms in the Construction Industry: Literature Review. Journal of Construction Engineering and Management, doi.org/10.1061/(ASCE)CO.1943-7862.0001353

Chan, A. P. C., Darko, A., Olanipekun, A. O., \& Ameyaw, E. E. (2018). Critical barriers to green building technologies adoption in developing countries: The case of Ghana. Journal of Cleaner Production, 172, 1067-1079.

Chan, E. H., Qian, Q. K., \& Lam, P. T. (2009). The market for green building in developed Asian cities - the perspectives of building designers. Energy Policy, 37(8), 3061-3070.

Chudley, R., \& Greeno, R. (2013). Building construction handbook. Routledge.

Darko, A. \& Chan, A. P. C (2017). Strategies to promote green building technologies adoption in developing countries: The case of Ghana. Building and Environment, 130, 74-84.

De Jong, M., Henry, W. P., \& Stansbury, N. (2009). Eliminating corruption in our engineering/construction industry. Leadership and Management in Engineering, 9(3), 105111.

Fellows, R. F., \& Liu, A. M. (2015). Research methods for construction. John Wiley \& Sons.

Harmon, K. M. (2003). Resolution of construction disputes: A review of current methodologies. Leadership and Management in Engineering, 3(4), 187-201.

Harris, F., \& McCaffer, R. (2013). Modern construction management. John Wiley \& Sons.

Hendrickson, C., \& Au, T. (2008). Project management for construction: Fundamental concepts for owners, engineers, architects, and builders. Available at: http://pmbook.ce.cmu.edu/03_The_Design_And_Construction_Process.html (Accessed on 20 December 2017) 
Hoxley, M. (2008). "Questionnaire design and factor analysis." Advanced research methods in the built environment, A. Knight and L. Ruddock, eds., Wiley-Blackwell, Chichester, U.K.,122134.

Hwang, B. G., Shan, M., Xie, S., \& Chi, S. (2017). Investigating residents' perceptions of green retrofit program in mature residential estates: The case of Singapore. Habitat International, 63, 103-112.

Kim, T. K. (2015). T test as a parametric statistic. Korean journal of anesthesiology, 68(6), 540-546.

Lam, P. T., Chan, E. H., Ann, T. W., Cam, W. C., \& Jack, S. Y. (2015). Applicability of clean development mechanism to the Hong Kong building sector. Journal of cleaner production, 109, 271-283.

Ling, F. Y. Y., Ong, S. Y., Ke, Y., Wang, S., \& Zou, P. (2014). Drivers and barriers to adopting relational contracting practices in public projects: Comparative study of Beijing and Sydney. International Journal of Project Management, 32(2), 275-285.

Le, Y., Shan, M., Chan, A. P., \& Hu, Y. (2014). Investigating the causal relationships between causes of and vulnerabilities to corruption in the Chinese public construction sector. Journal of construction engineering and management, 140(9), 05014007.

Levy, S. M. (2010). Construction process planning and management: An owner's guide to successful projects. Butterworth-Heinemann.

Li, Y. Y., Chen, P. H., Chew, D. A. S., Teo, C. C., \& Ding, R. G. (2011). Critical project management factors of AEC firms for delivering green building projects in Singapore. Journal of construction engineering and management, 137(12), 1153-1163.

Locatelli, G., Mariani, G., Sainati, T., \& Greco, M. (2017). Corruption in public projects and megaprojects: There is an elephant in the room!. International Journal of Project Management, 35(3), 252-268.

Menkel-Meadow, C. (1996). When dispute resolution begets disputes of its own: conflicts among dispute professionals. Ucla L. Rev., 44, 1871.

Merritt, F. S., \& Ricketts, J. T. (2001). Building design and construction handbook (Vol. 13). New York, NY: McGraw-Hill.

Kenny, C. (2009). Transport construction, corruption and developing countries. Transport Reviews, 29(1), 21-41.

Kibert, C. J. (2016). Sustainable construction: green building design and delivery. John Wiley \& Sons.

Krishnan, C. (2009). Combating corruption in the construction and engineering sector: The role of transparency international. Leadership and Management in Engineering, 9(3), 112-114.

Krishnan, C. (2010). Tackling corruption in the construction. Available at https://www.transparency.org.uk/wp-content/plugins/downloadattachments/includes/download.php?id=1032. (Accessed on 15th November 2017).

Osei-Kyei, R., \& Chan, A. P. (2017). Comparative Analysis of the Success Criteria for Public-Private Partnership Projects in Ghana and Hong Kong. Project Management Journal, 48(4), 80-92.

Ott, R. L., \& Longnecker, M. T. (2015). An introduction to statistical methods and data analysis. Nelson Education.

Owusu, E. K., Chan, A. P., \& Shan, M. (2017). Causal Factors of Corruption in Construction Project Management: An Overview. Science and engineering ethics, 1-31.

PII - Pacific Invasive Initiative (2011). The Project Process Stages. Available at: http://pacificinvasivesinitiative.org/rk/project/1_Project_Selection.html (Accessed on 20 December 2017)

Santos, J. R. A. (1999). Cronbach's alpha: A tool for assessing the reliability of scales. Journal of extension, 37(2), 1-5. 
Seifert, B. M. (2005). International construction dispute adjudication under international federation of consulting engineers conditions of contract and the dispute adjudication board. Journal of professional issues in engineering education and practice, 131(2), 149-157.

Shakantu, W.M.W. (2006). Corruption in the construction industry: Forms, susceptibility and possible solutions. CIDB 1st Postgraduate Conference 2003. South Africa: Port Elizabeth, 274-283.

Shan, M., Hwang, B. G., \& Wong, K. S. N. (2017a). A preliminary investigation of underground residential buildings: Advantages, disadvantages, and critical risks. Tunnelling and Underground Space Technology, 70, 19-29.

Shan, M., Le, Y., Yiu, K. T., Chan, A. P., \& Hu, Y. (2017b). Investigating the underlying factors of corruption in the public construction sector: Evidence from China. Science and engineering ethics, 23(6), 1643-1666.

Siegel, S., Castellan, N.J., 1988. Nonparametric Statistics for the Behavioral Sciences, second ed. McGraw-Hill, New York

Stansbury C and Stansbury N. (2008). Examples of Corruption in Infrastructure. Global Infrastructure Anti- Global Infrastructure Anti-Corruption Centre.

http://www.giaccentre.org/documents/giacc.corruptionexamples.pdf. Accessed 1st October 2018

Stansbury, N. (2009). United Kingdom Anticorruption Forum. Leadership and Management in Engineering, 9(3), 115-118.

Tabish, S. Z. S., \& Jha, K. N. (2011). Analyses and evaluation of irregularities in public procurement in India. Construction Management and Economics, 29(3), 261-274.

Tan, W.C.K., (2011). Practical Research Methods. Pearson Custom, Singapore

TI (Transparency International). (2018). “Anti-corruption glossary, forms of corruption.” Available at: http://www.transparency.org/glossary. (Accessed on 29 September 2018).

Transparency International (2006). The Role of Transparency International in Fighting Corruption in Infrastructure. Annual Bank Conference on Development Economics, Tokyo, 29-30 May 2006. Rethinking Infrastructure for Development..

Vee, C., \& Skitmore, C. (2003). Professional ethics in the construction industry. Engineering,

Construction and Architectural Management, 10(2), 117-127.

Watts, A. (2016). Modern construction handbook. Birkhäuser.

Willar, D., Trigunarsyah, B., \& Coffey, V. (2016). Organisational culture and quality management system implementation in Indonesian construction companies. Engineering, Construction and Architectural Management, 23(2), 114-133.

Wilson, J. M. (2003). Gantt charts: A centenary appreciation. European Journal of Operational Research, 149(2), 430-437.

Wong, J. K. W., San Chan, J. K., \& Wadu, M. J. (2016). Facilitating effective green procurement in construction projects: An empirical study of the enablers. Journal of cleaner production, 135, 859-871.

Zhang, B., Le, Y., Xia, B., \& Skitmore, M. (2016). Causes of business-to-government corruption in the tendering process in China. Journal of Management in Engineering, 33(2), 05016022.

Zuo, J., \& Zillante, G. (2005). Project culture within construction projects: a literature review. In 13th International Group for Lean Construction Conference: Proceedings (p. 353). International Group on Lean Construction. 


\section{TABLES}

Table 1: Respondents Profiles

\begin{tabular}{llll}
\hline Profiles & Categories & Number of respondents & Percentage \\
\hline Background & Public Sector & 32 & 72.7 \\
& Private Sector & 7 & 15.9 \\
& Both & 5 & 11.4 \\
& Total & $\mathbf{4 4}$ & $\mathbf{1 0 0 . 0}$ \\
Professional & Engineer & 6 & 13.6 \\
Affiliation & Quantity Surveyor & 4 & 9.1 \\
& Contractor & 13 & 29.5 \\
& Architect & 2 & 4.5 \\
& Procurement Expert & 1 & 2.3 \\
& Researchers with industrial & 18 & 40.9 \\
& experience & & \\
Working & Total & $\mathbf{4 4}$ & $\mathbf{1 0 0 . 0}$ \\
Experience & 1-5 years & 9 & 20.5 \\
& 6-10 years & 8 & 18.2 \\
& 11-20 years & 13 & 29.5 \\
& Above 20 years & 14 & 31.8 \\
Region & Total & $\mathbf{4 4}$ & $\mathbf{1 0 0 . 0}$ \\
& Developed country & 27 & 61.4 \\
& Developing Country & 17 & 38.6 \\
& Total & $\mathbf{4 4}$ & $\mathbf{1 0 0 . 0}$ \\
\hline
\end{tabular}


Table 2: Developing countries and the developed comparison

\begin{tabular}{|c|c|c|c|c|c|c|c|c|c|c|c|c|c|c|c|}
\hline \multirow[t]{2}{*}{ No } & \multirow{2}{*}{$\begin{array}{l}\text { Construction } \\
\text { Process }\end{array}$} & \multirow[t]{2}{*}{ Code } & \multicolumn{5}{|c|}{ Overall scores } & \multicolumn{4}{|c|}{ Developing } & \multicolumn{4}{|c|}{ Developed } \\
\hline & & & Mean & Std. Dev & p-value & SWT & Rank & Mean & Std. Dev & p-value & Rank & Mean & Std. Dev & p-value & Rank \\
\hline 1 & Conception & CP1 & 2.07 & 0.997 & $.000^{\mathrm{a}}$ & $.000^{\mathrm{b}}$ & 11 & 2.00 & 1.060 & $0.001^{\mathrm{a}}$ & 11 & 2.11 & 0.97402 & $0.000^{\mathrm{a}}$ & 10 \\
\hline 2 & $\begin{array}{l}\text { Project selection } \\
\text { stage }\end{array}$ & $\mathrm{CP} 2$ & 2.36 & 1.143 & $.000^{\mathrm{a}}$ & $.000^{\mathrm{b}}$ & 10 & 2.59 & 1.003 & 0.110 & 9 & 2.22 & 1.21950 & $0.003^{\mathrm{a}}$ & 7 \\
\hline 3 & Planning stage & $\mathrm{CP} 3$ & 2.25 & 1.123 & $.000^{\mathrm{a}}$ & $.000^{\mathrm{b}}$ & 9 & 2.41 & 1.003 & $0.028^{\mathrm{a}}$ & 10 & 2.15 & 1.19948 & $0.001^{\mathrm{a}}$ & 8 \\
\hline 4 & Inspection stage & $\mathrm{CP} 4$ & 2.48 & 1.171 & $.000^{\mathrm{a}}$ & $.000^{\mathrm{b}}$ & 7 & 3.06 & 0.826 & 0.773 & 7 & 2.11 & 1.21950 & $0.001^{\mathrm{a}}$ & 11 \\
\hline 5 & Design Stage & $\mathrm{CP5}$ & 2.41 & 1.127 & $.000^{\mathrm{a}}$ & $.000^{\mathrm{b}}$ & 8 & 2.71 & 1.104 & 0.289 & 8 & 2.22 & 1.12090 & $0.001^{\mathrm{a}}$ & 6 \\
\hline 6 & $\begin{array}{l}\text { Pre-qualification } \\
\text { and tender }\end{array}$ & CP6 & 2.91 & 1.394 & $.007^{\mathrm{a}}$ & $.000^{\mathrm{b}}$ & 2 & 3.71 & 1.159 & $0.023^{\mathrm{a}}$ & 2 & 2.41 & 1.30853 & $0.026^{\mathrm{a}}$ & 1 \\
\hline 7 & $\begin{array}{l}\text { Contact signing } \\
\text { stage }\end{array}$ & $\mathrm{CP} 7$ & 2.61 & 1.450 & $.000^{\mathrm{a}}$ & $.000^{\mathrm{b}}$ & 6 & 3.35 & 1.320 & 0.287 & 5 & 2.15 & 1.35032 & $0.003^{\mathrm{a}}$ & 9 \\
\hline 8 & Project execution & CP8 & 3.00 & 1.414 & $.024^{\mathrm{a}}$ & $.000^{\mathrm{b}}$ & 1 & 3.94 & 0.966 & $0.001^{\mathrm{a}}$ & 1 & 2.41 & 1.33760 & $0.030^{\mathrm{a}}$ & 2 \\
\hline 9 & Service Delivery & $\mathrm{CP} 9$ & 2.82 & 1.334 & $.002^{\mathrm{a}}$ & $.000^{\mathrm{b}}$ & 3 & 3.53 & 1.124 & 0.070 & 3 & 2.37 & 1.27545 & $0.016^{\mathrm{a}}$ & 4 \\
\hline 10 & $\begin{array}{l}\text { Project } \\
\text { Maintenance }\end{array}$ & CP10 & 2.65 & 1.274 & $.000^{\mathrm{a}}$ & $.000^{\mathrm{b}}$ & 5 & 3.18 & 1.131 & 0.529 & 6 & 2.33 & 1.27098 & $0.011^{\mathrm{a}}$ & 5 \\
\hline 11 & Dispute resolution & CP11 & 2.82 & 1.40220 & $.002^{\mathrm{a}}$ & $.000^{\mathrm{b}}$ & 3 & 3.53 & 1.374 & 0.132 & 4 & 2.37 & 1.24493 & $0.014^{\mathrm{a}}$ & 3 \\
\hline Note: & $\begin{array}{l}\text { a indicates data wit } \\
\text { b SWT represents } \\
\text { Cronbach's Alpha } \\
\text { Kendall's W }=0.10\end{array}$ & $\begin{array}{l}\text { signific } \\
\text { hapiro-V } \\
\text { overall) } \\
\text { 5; Asym }\end{array}$ & $\begin{array}{l}\text { int resul } \\
\text { ilk test; } \\
0.935 \text {; } \\
\text { Sig. o }\end{array}$ & $\begin{array}{l}\text { of one-sa } \\
\text { WT result } \\
\text { eveloping } \\
\text { Kendall's }\end{array}$ & $\begin{array}{l}\text { ple t-test } \\
\text { indicates } \\
0.788 ; \mathrm{D} \\
=0.000\end{array}$ & $\begin{array}{l}<0.05 \\
\text { ta were } \\
\text { eloped } \\
\mathrm{f}=10 ;\end{array}$ & $\begin{array}{l}\text { atistic } \\
0.961 \\
\text { tual ce }\end{array}$ & $\begin{array}{l}\text { ly signi } \\
\mathrm{J}=44 . \\
\text { ulated }\end{array}$ & cantly dif & $\begin{array}{l}\text { ant from } \\
\text { lue }=46.0\end{array}$ & $\begin{array}{l}\text { distr } \\
\text { ritical } \\
\end{array}$ & n & lue at $\mathrm{p}-$ & $e=18.31$ & \\
\hline
\end{tabular}


Table 3: Mann-Whitney U test on the CP stages

\begin{tabular}{|c|c|c|c|c|c|c|c|c|c|c|c|}
\hline Test statistics ${ }^{\mathrm{a}}$ & $\mathrm{CP} 1$ & $\mathrm{CP} 2$ & CP3 & $\mathrm{CP} 4$ & $\mathrm{CP5}$ & CP6 & CP7 & CP8 & CP9 & CP10 & CP11 \\
\hline $\begin{array}{c}\text { Mann-Whitney } \\
\text { U }\end{array}$ & 209.000 & 180.000 & 193.500 & 123.000 & 173.000 & 111.500 & 116.500 & 89.000 & 119.000 & 147.500 & 121.000 \\
\hline $\begin{array}{c}\text { Wilcoxon W } \\
\text { Z }\end{array}$ & $\begin{array}{c}362.000 \\
-.519\end{array}$ & $\begin{array}{c}558.000 \\
-1.242\end{array}$ & $\begin{array}{c}571.500 \\
-.901\end{array}$ & $\begin{array}{c}501.000 \\
-2.654\end{array}$ & $\begin{array}{c}551.000 \\
-1.416\end{array}$ & $\begin{array}{c}489.500 \\
-2.937\end{array}$ & $\begin{array}{c}494.500 \\
-2.810\end{array}$ & $\begin{array}{c}467.000 \\
-3.545\end{array}$ & $\begin{array}{c}497.000 \\
-2.755\end{array}$ & $\begin{array}{c}525.500 \\
-2.051\end{array}$ & $\begin{array}{c}499.000 \\
-2.680\end{array}$ \\
\hline $\begin{array}{l}\text { Asymp. Sig. } \\
\text { (2-tailed) }\end{array}$ & 0.604 & 0.214 & 0.368 & $0.008^{\mathrm{b}}$ & 0.157 & $0.003^{b}$ & $0.005^{b}$ & $0.000^{\mathrm{b}}$ & $0.006^{\mathrm{b}}$ & $0.040^{\mathrm{b}}$ & $0.007^{\mathrm{b}}$ \\
\hline
\end{tabular}

a. Grouping Variable: Contextual groups (i.e., developed and developing countries)

b. Results indicating significant differences (Data with significant results) 
Table 4: Significant test comparisons for the CP stages

\begin{tabular}{|c|c|c|c|c|c|c|c|c|c|c|c|}
\hline Code & CP8 & CP6 & CP9 & CP11 & CP10 & CP7 & $\mathrm{CP} 4$ & $\mathrm{CP} 2$ & CP5 & CP3 & $\mathrm{CP} 1$ \\
\hline CP8 & - & 0.560 & 0.129 & 0.256 & $0.033^{\mathrm{a}}$ & $0.018^{\mathrm{a}}$ & $0.002^{\mathrm{a}}$ & $0.002^{\mathrm{a}}$ & $0.004^{\mathrm{a}}$ & $0.001^{\mathrm{a}}$ & $0.000^{\mathrm{a}}$ \\
\hline CP6 & & - & 0.476 & 0.540 & 0.141 & 0.061 & $0.043^{\mathrm{a}}$ & $0.016^{\mathrm{a}}$ & $0.018^{\mathrm{a}}$ & $0.001^{\mathrm{a}}$ & $0.002^{\mathrm{a}}$ \\
\hline CP9 & & & - & 0.937 & 0.265 & 0.326 & $0.039^{\mathrm{a}}$ & $0.030^{\mathrm{a}}$ & $0.023^{\mathrm{a}}$ & $0.005^{\mathrm{a}}$ & $0.002^{\mathrm{a}}$ \\
\hline CP11 & & & & - & 0.354 & 0.319 & 0.086 & 0.072 & $0.040^{\mathrm{a}}$ & $0.006^{\mathrm{a}}$ & $0.006^{\mathrm{a}}$ \\
\hline CP10 & & & & & - & 0.867 & 0.319 & 0.095 & 0.146 & $0.021^{\mathrm{a}}$ & $0.008^{a}$ \\
\hline $\mathrm{CP} 7$ & & & & & & - & 0.473 & 0.119 & 0.303 & 0.066 & $0.017^{\mathrm{a}}$ \\
\hline $\mathrm{CP} 4$ & & & & & & & - & 0.442 & 0.557 & 0.190 & $0.035^{\mathrm{a}}$ \\
\hline $\mathrm{CP} 2$ & & & & & & & & - & 0.802 & 0.509 & 0.083 \\
\hline CP5 & & & & & & & & & - & 0.256 & 0.066 \\
\hline CP3 & & & & & & & & & & - & 0.298 \\
\hline $\mathrm{CP} 1$ & & & & & & & & & & & - \\
\hline
\end{tabular}

Note: ${ }^{a}$ Wilcoxon's signed rank test result is significant at $\mathrm{p}$-value $<.05$, indicating that the stage-by-stage comparisons were statistically different 


\section{FIGURES}

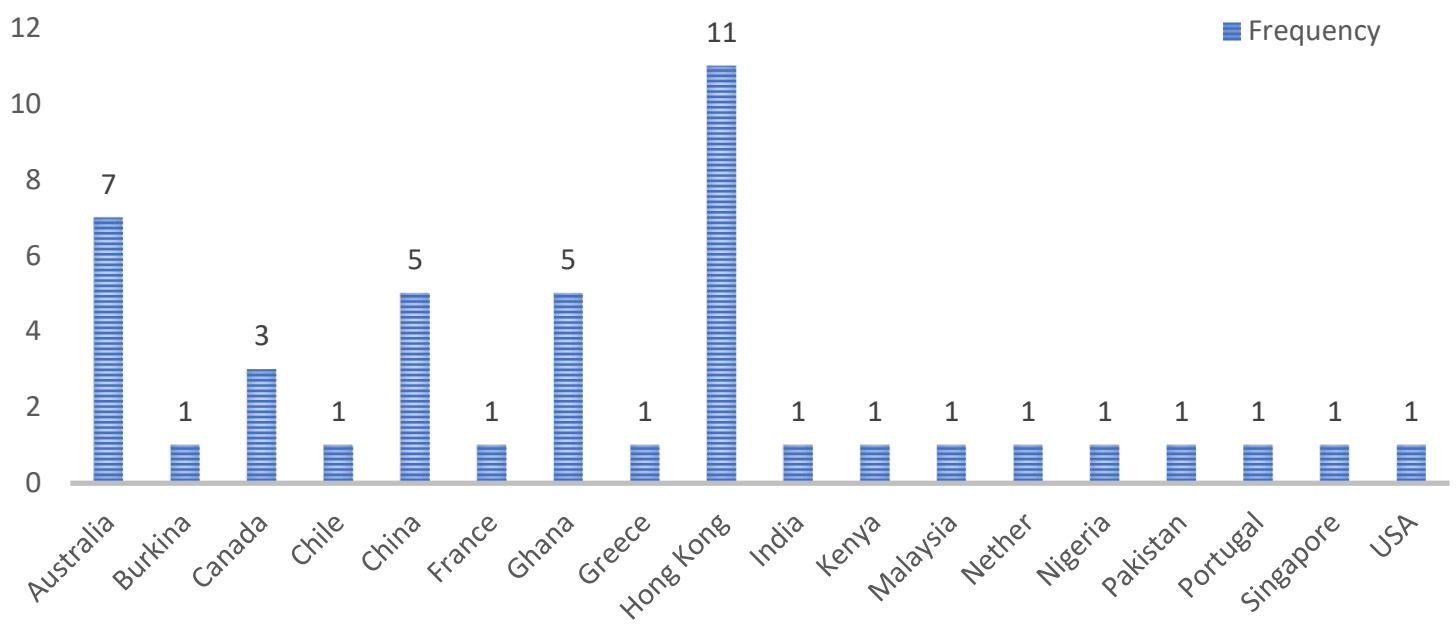

Figure 1: Countries of respondents 


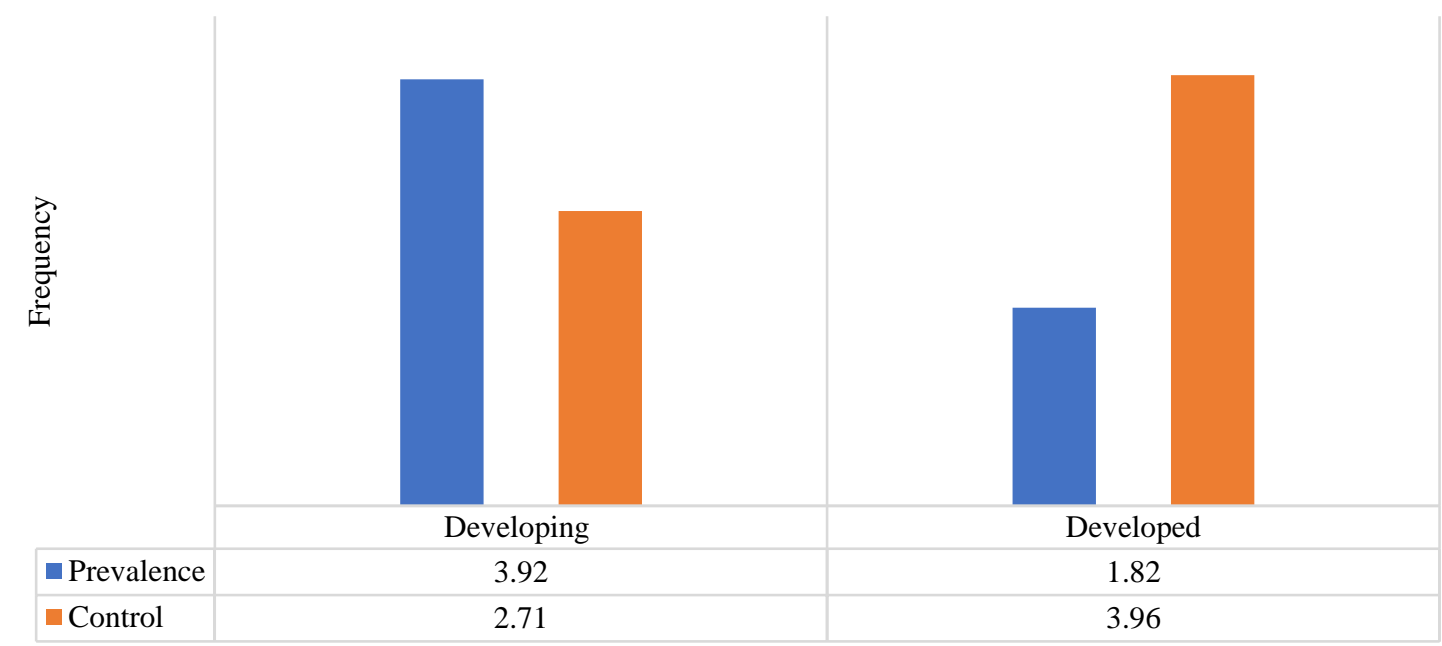

Figure 2: Graphical presentation of corruption prevalence and control for construction projects 


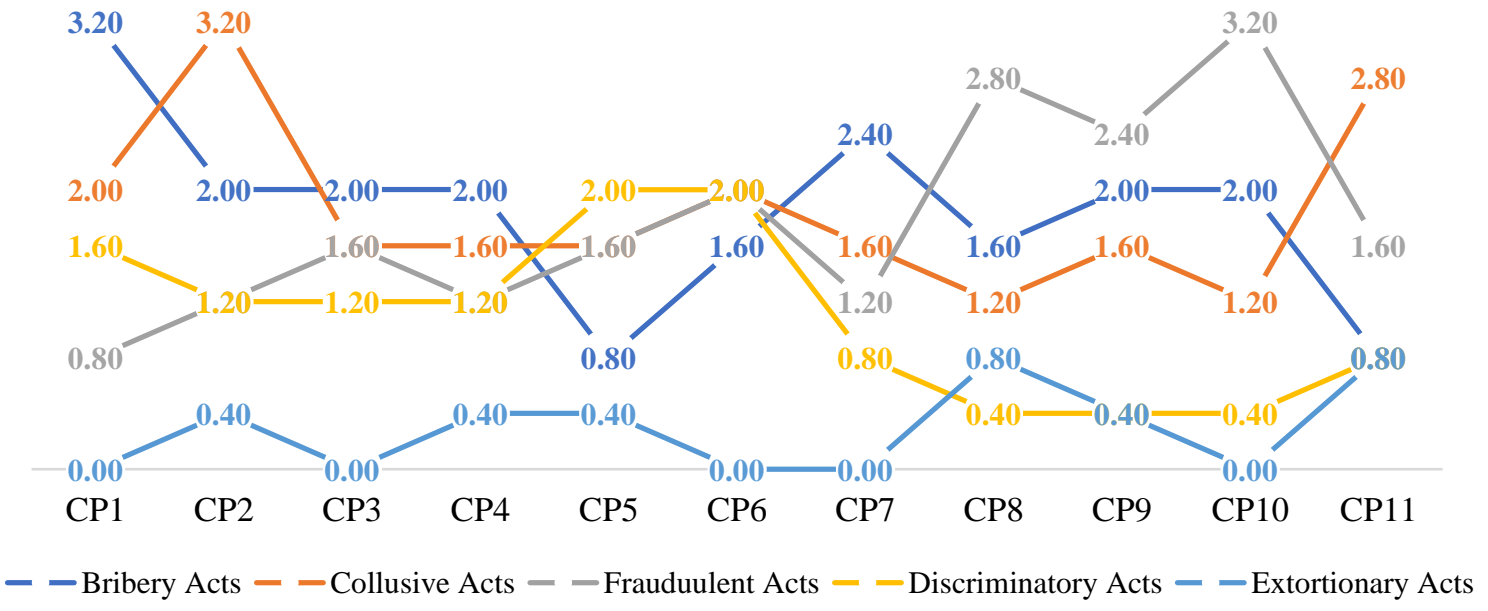

Figure 3: CFs prevalence throughout the construction process for developed countries 


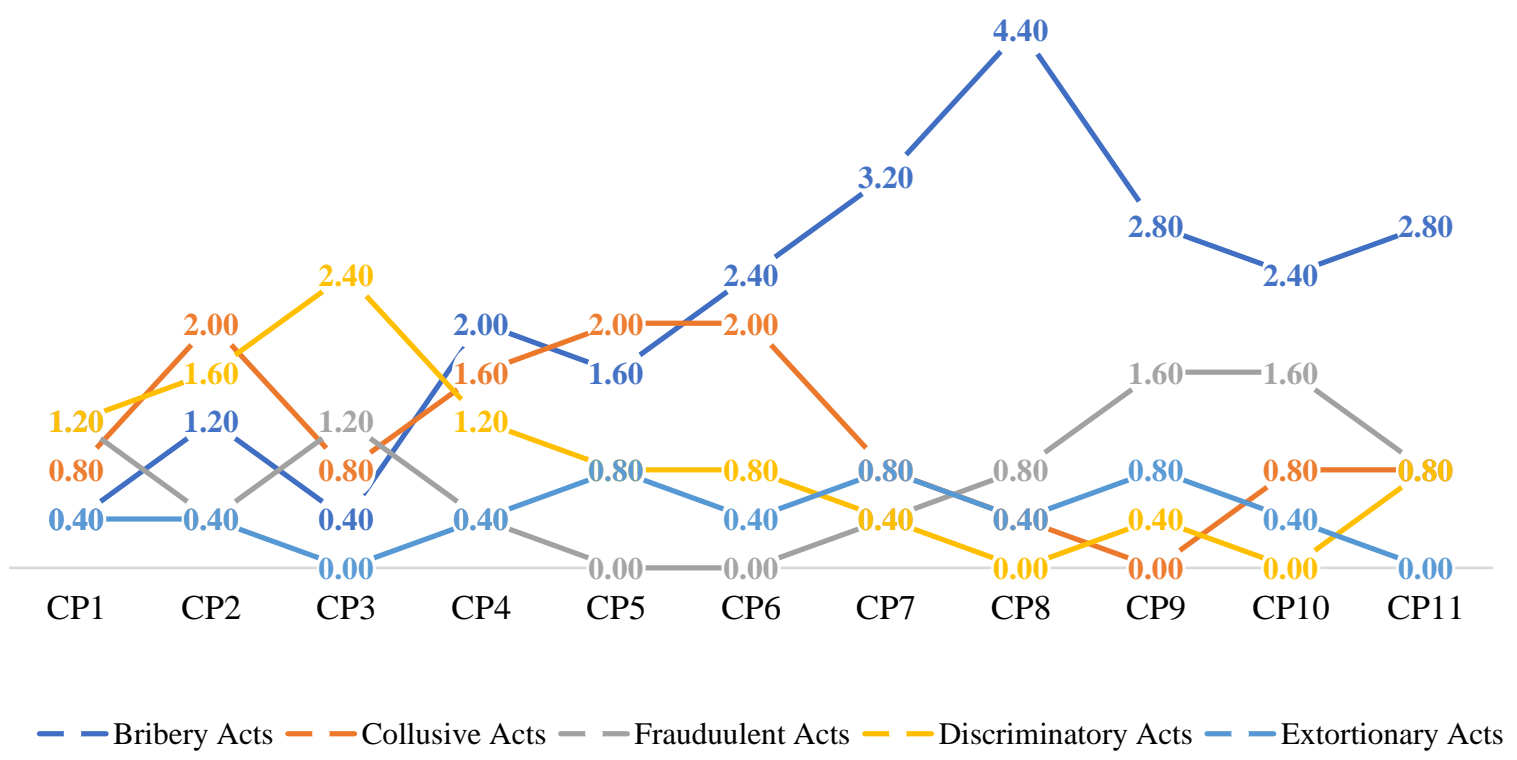

Figure 4: CFs prevalence throughout the construction process for developing countries 